\title{
Use of fluorescent probes to follow membrane traffic in nerve terminals
}

\author{
C. Guatimosim, \\ M.A. Romano-Silva, \\ M.V. Gomez and \\ M.A.M. Prado
}

\author{
Laboratório de Neurofarmacologia, Departamento de Farmacologia, \\ Instituto de Ciências Biológicas, Universidade Federal de M inas Gerais, \\ Belo Horizonte, MG, Brasil
}

\section{Correspondence \\ M.A.M. Prado \\ Laboratório de Neurofarmacologia \\ Departamento de Farmacologia \\ ICB, UFM G \\ Av. Antonio Carlos, 6627 \\ 31270-901 Belo Horizonte, M G \\ Brasil \\ Fax: + 55-31-499-2695 \\ E-mail: mprado@icb.ufmg.br}

Presented at the International Symposium: Biological Applications of Confocal Microscopy, Belo

Horizonte, MG, Brasil, April 6-8, 1998.

Research supported by PADCT, PRPq-UFMG, FAPEMIG, CNPq, FINEP and PRONEX.

Received May 14, 1998 Accepted June 3, 1998

\begin{abstract}
Optical tracers in conjunction with fluorescence microscopy have become widely used to follow the movement of synaptic vesicles in nerve terminals. The present review discusses the use of these optical methods to understand the regulation of exocytosis and endocytosis of synaptic vesicles. The maintenance of neurotransmission depends on the constant recycling of synaptic vesicles and important insights have been gained by visualization of vesicles with the vital dye FM1-43. A number of questions related to the control of recycling of synaptic vesicles by prolonged stimulation and the role of calcium to control membrane internalization are now being addressed. It is expected that optical monitoring of presynaptic activity coupled to appropriate genetic models will contribute to the understanding of membrane traffic in synaptic terminals.
\end{abstract}

\section{Introduction}

In the nervous system, the most common type of communication between cells is provided by local release of chemical mediators known as neurotransmitters. The activity of specific vesicular transporters accumulates these chemical messengers into synaptic vesicles from where they are released to the synaptic cleft. The release of neurotransmitters depends on the fusion (exocytosis) of the synaptic vesicle membrane with specialized regions of the plasma membrane. Furthermore, in order to maintain constant the size of the membrane surface and especially to avoid depletion of the vesicle pool, synaptic vesicles are retrieved (endocytosis), recycled locally and refilled with neurotransmitter (1$3)$. Over the last six years, the introduction of
Key words

- Laser scanning

confocal microscopy

- FM 1-43

- Exocytosis

- Synaptic vesicles

- Endocytosis optical tracer methods has been responsible for improving our understanding about membrane trafficking in nerve terminals $(4,5)$. Since nerve endings are generally too small for electrophysiological measurements, optical analysis of individual active zones is a promising technique to monitor membrane dynamics in intact terminals, and provides an attractive alternative to follow exo-endocytosis linked to transmitter release (4).

In this review, we focus on recent advances on how the use of optical tracers and fluorescence microscopy has helped to answer important questions related to the release of neurotransmitters.

\section{Proteins involved in exocytosis}

It is well established that small synaptic 
vesicles store classical neurotransmitters for release (3). Under resting conditions, some of the vesicles can be found docked at specialized plasmalemmal sites (active zones). The arrival of a nerve impulse in the terminal region is followed by calcium influx through different subtypes of voltage-activated calcium channels preferentially located in the active zone $(6,7)$. A rise in intracellular calcium increases the probability of fusion of synaptic vesicles with the axolemma in the active zone, most likely due to a myriad of protein-protein interactions (8). This issue has been the focus of attention of several reviews in the past years and will not be covered in depth here; readers are directed to recent reviews of this topic $(8,9)$.

Dodge Jr. and Rahamimoff (10) demonstrated a non-linear dependence of the excitatory post-synaptic potential on the external calcium concentration. They concluded that a cooperative action of four calcium ions is necessary to stimulate quantal release of neurotransmitters, suggesting the participation of a calcium receptor in the exocytotic machinery. One of the proteins that fulfill many of the requirements for a calcium sensor is synaptotagmin I. This protein has two C2 domains that bind phospholipids and calcium $(11,12)$. Indeed, genetic and biochemical evidence has clearly shown the need of functional synaptotagmin I for fast exocytosis in a number of preparations, although its postulated role as a calcium sensor may be shared by other members of the synaptotagmin family (13). Unexpectedly, synaptotagmin has also been shown to have a role in endocytosis of synaptic vesicles $(14,15)$.

It is likely that a number of protein-protein interactions take place during the synaptic vesicle cycle. Synaptobrevin, syntaxin and SNAP-25, proteins present in the synaptic vesicle and plasma membrane, have been shown to form a stable complex in vitro (16). This may form the basis for binding of cytosolic proteins, soluble NSF attachment pro- teins (SNAPs) and NSF, to form a core complex which is of importance for exocytosis (16). The three former proteins are also the targets of clostridium toxins, proteases that impair synaptic transmission (17), which strongly implicates synaptobrevin, syntaxin and SNAP-25 in exocytosis.

There are controversies concerning the role played by each synaptic protein in mobilization, docking, priming, fusion, fission and recycling of synaptic vesicles. It is hoped that functional optical assays used concomitantly with appropriate genetic models could help understand some of the roles of synaptic proteins in membrane traffic.

\section{O ptical analysis of exocytosis}

Several probes useful in following presynaptic membrane activity in live nerve terminals have been described (5). So far, the most popular way to visualize vesicle dynamics in synaptic terminals has been the use of the styryl dye FM1-43 (5). The evidence that supports the proposed mechanism for staining with FM1-43 can be summarized as follows: axonal terminals stain in an activity-dependent fashion with FM1-43, which generates fluorescent puncta (Figure 1A) located in close opposition to nicotinic receptors at the neuromuscular junction (NMJ) (4), and which colocalizes with synapsin I in hippocampal terminals (18).

In addition, ultrastructural analysis of FM143 labeled terminals, with a method devised to visualize the dye using electron microscopy, shows that FM1-43 is primarily present inside synaptic vesicles (19). Thus, this and other evidence $(5,20)$ are consistent with the proposal that, due to their amphipathic nature, FM dyes bind to the outer leaflet of membranes but cannot cross it (4). During stimulation, the synaptic vesicle membrane becomes exposed to the synaptic cleft and incorporates the dye, which is subsequently internalized by endocytosis (Figure 1A). 

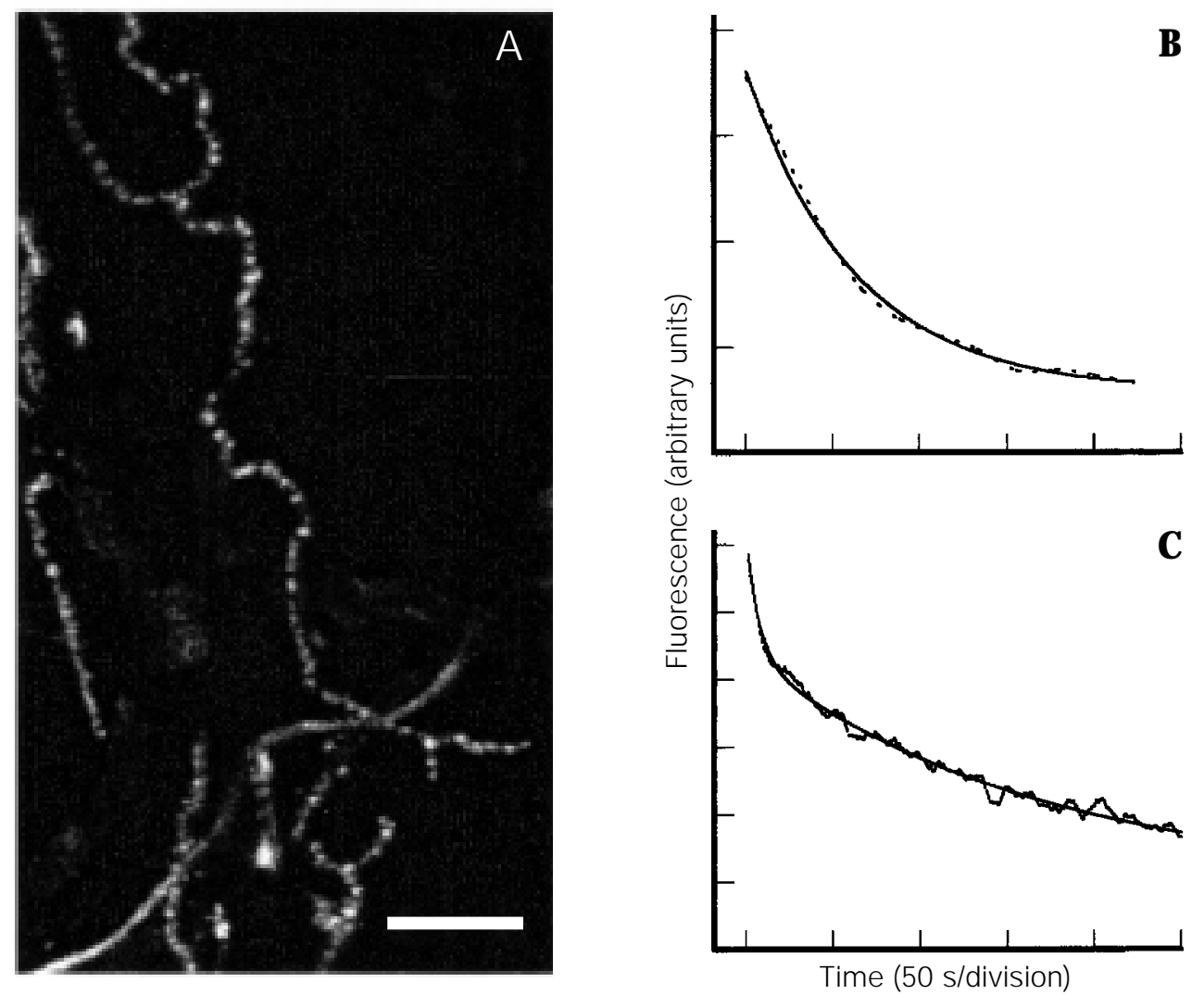

Figure 1 - Staining and destaining of frog motor nerve terminals labeled with FM 1-43.

A, Motor nerve terminals from frog cutaneous pectoris muscle were labeled with FM 1-43 during electrical stimulation of the nerve ( $20 \mathrm{~Hz}, 5 \mathrm{~min}$ ). After a washing period, FM 1-43-stained terminals were selected using a Zeiss fluorescence microscope (axiovert 100) with a 40-X water immersion objective (1.2 NA). The nerve terminals were imaged using an MRC 1024-BioRad argon UV laser scanning confocal microscope coupled to the Zeiss microscope. The preparation was excited at $488 \mathrm{~nm}$ and light emitted above $515 \mathrm{~nm}$ was collected for analysis. This figure shows a low magnification confocal image obtained after reconstruction of a series of Z-sections ( $0.5 \mu \mathrm{m}$ apart, iris at 1.7$)$. Note the presence of several fluorescent puncta, each of which corresponds to a cluster of synaptic vesicles labeled with FM 1-43. Bar, $30 \mu \mathrm{m}$.

B, FM 1-43-labeled motor nerve terminals such as those described in A were electrically stimulated through the nerve $(20 \mathrm{~Hz}, 5 \mathrm{~min})$ in dye-free medium. The fluorescent puncta destained progressively during stimulation and the loss of fluorescence was quantified as mean fluorescence intensity in 256 levels of grey. The dashed curve represents the mean intensity of fluorescence destaining of 17 fluorescent puncta and the solid line corresponds to the fitting of the destaining curve by a single exponential equation (fluorescence $(t)$ $=A e^{-t / \tau}+C$ ). The destaining curve presented $a \tau=58 \pm 4 \mathrm{~s}$ (data from Ref. 32).

C, Rat cerebrocortical synaptosomes were labeled with FM 1-43 according to Ref. 27. After labeling, the synaptosomes were washed in dye-free medium and transferred to a fluorimeter cuvette. Fluorescence measurements were performed with a PTI spectrofluorimeter, at $488 \mathrm{~nm}$ (excitation) and $560 \mathrm{~nm}$ (emission). FM 1-43-labeled synaptosomes were destained under depolarization with $60 \mathrm{mM} \mathrm{KCl}$. The destaining curve (dashed line) represents the mean of twelve independent experiments and is described by a double exponential equation (fluorescence $(t)=A_{1} e^{-t / \tau 1}+A_{2} e^{-t / \tau 2}+C$ ), with time constants of $8 \pm 1 \mathrm{~s}$ and $129 \pm 9 \mathrm{~s}$ for the first and second components, respectively. The solid line represents the fitting of the FM1-43destaining curve for synaptosomes. 
A key characteristic of FM dyes is that they are several-fold more fluorescent when dissolved in the membrane than when in aqueous environment. Therefore, synaptic vesicle clusters labeled with FM1-43 are very bright (Figure 1A), but they dim due to dye release during exocytosis (4; see Figure $1 \mathrm{~B}$ and $\mathrm{C}$ ). Consequently, destaining follows most of the characteristics of neurotransmitter release $(21,22$; see Figure $1 \mathrm{~B}$ and $\mathrm{C})$.

Several model preparations are suitable for optical imaging of presynaptic activity with FM1-43. A number of studies have shown that FM1-43 staining and destaining are calcium dependent $(4,18,23-25)$. In fact, in hippocampal and cerebellar granule cells in culture, as well as in rat brain synaptosomes, FM1-43 measurements have been used to investigate the nature of calcium channels coupled to exocytosis $(23,26,27)$. Thus, in field stimulated cultured cells, Ntype calcium channels blocked by $\omega$ conotoxin GVIA have been shown to contribute distinctly to exocytosis in different populations of nerve endings (23). Two classes of channels may be present in the same nerve terminal and act in concert to trigger and regulate exocytosis (28). In cerebellar granule cells maintained in culture, identification of release sites and calcium imaging of neurites have also indicated a role for $\mathrm{N}$ - and $\mathrm{P} / \mathrm{Q}$ type calcium channels in exocytosis (29). Interestingly, $\mathrm{P} / \mathrm{Q}$ type calcium channels seemed to be more effectively coupled to FM2-10 exocytosis than N-type channels (29), confirming previous observations that the former may be more effectively coupled to neurotransmitter release (30). In synaptosomes depolarized with $\mathrm{KCl}$, only $\omega$-agatoxin IVA-sensitive channels seemed to participate in FM1-43 release, suggesting that $\mathrm{P} / \mathrm{Q}$ channels (the targets of $\omega$-agatoxin IVA) may be present in the majority of nerve terminals from rat cortex to control transmitter release (27).

Analysis of FM1-43 release from cultured neurons indicates that synaptic vesicle pool depletion (100 to 200 vesicles) occurs with a $\tau$ of $20 \mathrm{~s}$ at $10-\mathrm{Hz}$ stimulation (31). At the frog neuromuscular junction, pool depletion (500 to 1000 vesicles) occurs with a $\tau$ of 120 and $60 \mathrm{~s}$ at $10 \mathrm{~Hz}$ and $20 \mathrm{~Hz}$ of stimulation, respectively (22,32; see Figure $1 \mathrm{~B})$. FM1-43 release from frog NMJ can be fitted by a single exponential function at least during strong stimulation (22,32; see also Figure 1B). In contrast, kinetic analysis of FM143 release from synaptosomes shows two components of destaining: a fast component with a $\tau$ of $8 \pm 1 \mathrm{~s}$, which probably reflects the time for the dye to be released from the membranes of rapidly exocytosed vesicles, and a second component which releases dye much slower ( $\tau 129 \pm 9 \mathrm{~s}$; Figure 1C; 33). It is noteworthy that a recent abstract reports two rates of FM dye release for stimulated hippocampal neurons (34), similar to that observed in synaptosomes. Although these differences were unappreciated before, they may provide insight into the characteristics of exo-endocytosis of different preparations. For instance, dye release from synaptic vesicles probably slows down when unlabeled vesicles recycle back to the pool and start to compete for release sites in active zones. Thus, differences in exponential characteristics of dye release from the above preparations may underlie small differences in the rates of synaptic vesicle recycling and repriming.

FM1-43 can be used in cultured neuronal cells for the identification of synaptic contacting points $(35,36)$, allowing quantal analysis to be performed in single identified synapses. Furthermore, optical monitoring of exocytosis has produced two important observations. Firstly, Ryan et al. (37) examined dye uptake in cultured neurons that were exposed to protocols aimed to mimic the induction of long-term potentiation. Their results suggested that tetanic stimulation caused potentiation of synaptic vesicle turnover, possibly due to a retrograde messenger acting on the presynaptic terminal to in- 
crease exocytosis (37). Since one of the difficulties in assigning a locus to long-term potentiation has always been the inability to assess presynaptic activity directly, the use of FM1-43 may provide new paradigms to study synaptic plasticity. Further experiments performed by the same group (38) concerned dye internalization by only a few synaptic vesicles. The authors found that the characteristics of dye internalization are compatible with the quantal nature of transmitter release, again an issue that has always been difficult to address in central synapses due to technical limitations imposed by post-synaptic detection of transmitter release. Thus, optical methods have provided unique insights into pre-synaptic mechanisms.

However, alternative approaches to follow synaptic vesicle and secretory granule dynamics in living cells have also contributed to our knowledge of membrane traffic. One of these takes advantage of fluorophoroconjugated antibodies against intraluminal domains of synaptotagmin I (39) to label synaptic vesicles, thus providing a probe to monitor long-term changes in synaptic activity.

Recently, secretory granule movement has been assessed using the evanescent-wave setup of a laser beam that suffers total reflection on the coverslip/cell interface (40). Combining the use of fluorescent probes such as green-fluorescent protein-tagged chromogranin (40) and acridine orange spheres (41), in conjunction with evanescent-wave fluorescence microscopy, it was possible to follow the movement of the granules that are adjacent to the coverslip, beneath the plasmalemma (in a 300-nm thin layer of cytosol) in $\mathrm{PC} 12$ cells.

\section{O ptical analysis of synaptic vesicle recycling}

Studies of release of neurotransmitters and exocytosis have gained by the use of optical tracers such as FM1-43, but it is on the investigation of endocytosis and synaptic vesicle recycling that optical monitoring and confocal microscopy have had a greater impact. The fate of the membrane after exocytosis has been a difficult issue to investigate which was amenable only to electron microscopy in fixed cells. Optical methods allowed the investigation of the dynamics of synaptic vesicle endocytosis in living cells. A number of experiments performed with FM1-43 have led to the suggestion that after exocytosis recycled synaptic vesicles fully mix with the pool of pre-existing vesicles in a given vesicle cluster (21,31). However, synaptic vesicle clusters at the NMJ are quite stable, and it seems that little movement between vesicle clusters occurs, as shown by the lack of recovery of fluorescence after photobleaching experiments (42). It is of interest that a putative mechanism for the translocation of vesicles in the nerve terminal can be unmasked by the phosphatase inhibitor okadaic acid; however, how this mechanism works without pharmacological manipulation remains a mystery (43).

It is clear that endocytosis lags behind exocytosis (5), and that the synaptic vesicle needs some time to be competent for a novel cycle of exocytosis (5). In the NMJ, Betz and Bewick (22) used correlation between transmitter release and FM1-43 destaining to find that vesicles take on average $90 \mathrm{~s}$ to become competent for a new cycle of exocytosis. By using a time delay to expose FM1-43 after distinct protocols of nerve stimulation, $\mathrm{Wu}$ and Betz (44) determined the minimum endocytic time constant at about $20 \mathrm{~s}$ at the frog NMJ. This pulse-chase approach was also applied to cells in culture, and the estimated half-time for endocytosis was close to $20 \mathrm{~s}$ (31). In these cells, the internalized vesicle needs at least $15 \mathrm{~s}$ to become competent for release again, suggesting that the total recycling time for the synaptic vesicle pool may be as short as 35 to $45 \mathrm{~s}$ in hippocampal neurons (31). It is interesting that in a terminal specialized for the continuous secretion 
of neurotransmitters, the goldfish bipolar terminal, endocytosis measured by capacitance seems to occur faster, with a time constant of $2 \mathrm{~s}$ (45).

\section{Proteins involved in the endocytosis of synaptic vesicles}

There are a number of proteins that seem to be necessary for endocytosis of synaptic vesicles. Purification of vesicles from mammalian brain indicated that most recycled vesicles contain clathrin (46). In fact, early electron microscopy evidence had led to the proposal that synaptic vesicles internalize after exocytosis through clathrin-coated pits (1). Moreover, suppression of the $\alpha$-adaptin gene in Drosophila generates mutants with impaired synaptic transmission due to a defect of vesicle recycling (47). This gene codes for a protein that is part of AP-2, a protein complex that seems to work as an adapter for the interaction of clathrin with the synaptic vesicle membrane. It is noteworthy that the AP-2 binding site in synaptic vesicles is the putative exocytotic calcium sensor synaptotagmin (48). This result, together with evidence demonstrating lack of vesicle recycling during suppression of synaptotagmin activity $(14,15)$, indicates a fundamental role for synaptotagmin in endocytosis.

Another protein, dynamin, a GTPase that is concentrated in nerve terminals (49), seems to play a key role in reformation of synaptic vesicles. Impairment of the GTPase activity of dynamin in the temperature-sensitive mutant shibire affects neurotransmission and immobilizes the fly in non-permissive temperatures by arresting endocytosis (50). Blockage of GTP hydrolysis by dynamin with GTP $\gamma \mathrm{S}$ leads to the appearance of tubular membrane invaginations coated with dynamin rings, thus pointing to a role of dynamin in the fission of vesicles from the plasma membrane or from an endosomal intermediary (51).

Many other key proteins that interact with dynamin and/or clathrin are also required for the internalization of synaptic vesicle membrane. For example, amphiphysin is colocalized in nerve terminals with dynamin, interacting with the former by its SH3-domain. Recently, Shupliakov et al. (52) injected peptides that compete with amphiphysin for an SH3-binding site in dynamin and observed an impairment of synaptic vesicle endocytosis which resulted in depression of neurotransmitter release during prolonged stimulation. In addition, no dynamin rings were detected in the intermediate stage of endocytosis observed by blocking the interaction of amphiphysin with dynamin, suggesting that the former may act on the recruitment of dynamin during endocytosis (52).

It is thus possible that most of the endocytosis occurring in nerve endings is clathrin dependent; however, it is not known whether this works similarly to other clathrinmediated events or presents any specialization at nerve endings. A particular point of interest is whether the availability of proteins involved in clathrin targeting or assembly may become rate limiting, when large amounts of synaptic vesicle membrane have to be retrieved from the terminal membrane. Nonetheless, perturbations in vesicle recycling seem to rapidly impair neurotransmission, underlying the key role of recycling in maintaining the release of neurotransmitters.

\section{Regulation of synaptic vesicle recycling}

It has been postulated that synaptic vesicles may "kiss-and-run" the plasma membrane, without being completely incorporated into it (53). Optical imaging of endocytosis, however, has produced little evidence of the existence of this fast retrieval mechanism under physiological conditions, and most of the experimental results are consistent with the exposure of the vesicle lumen to the synaptic cleft at least for a few seconds 
$(44,54)$. However, at the NMJ, staurosporine has been reported to affect FM1-43 release in a manner that is consistent with a rapid opening and closure of a fusion pore, without complete flattening of the vesicle membrane (55).

Several factors may affect the rate of endocytosis during neuronal stimulation. For example, the duration of stimulation trains can delay the rate of endocytosis in frog NMJ (44). However, in cultured hippocampal cells, different periods ( 1 or $5 \mathrm{~s}$ at $20 \mathrm{~Hz}$ ) of stimulation do not seem to change much the bulk endocytosis, although the initial rate of membrane internalization seems to be faster with longer periods of activity ( $5 \mathrm{~s}$ at $20 \mathrm{~Hz}$ ) (54). Interestingly, in this preparation, endocytosis seems to occur twice as fast at more physiological temperatures.

One of the factors that could have an important influence on different aspects of membrane cycling is the localized influx of calcium, which is necessary to elicit exocytosis. An early report using black widow spider venom shows that exocytosis can be evoked in the absence of calcium, but under these conditions membrane internalization is severely impaired in poisoned terminals. This ultrastructural study led to the suggestion that endocytosis involves a calciumdependent step (56).

It is somewhat tricky to separate the actions of calcium from exocytosis and endocytosis, since calcium is a requirement for the former, and regulated endocytosis occurs only after synaptic vesicle incorporation into the plasma membrane. Thus, there is some controversy whether calcium plays a role in endocytosis during physiological stimulation. The internalization of FM1-43 in hippocampal cells does not seem to be much altered by treatments aimed to change the intracellular calcium concentration $(18,54)$. Consistent with that, the rate of dye internalization does not seem to correlate with the instantaneous level of intraterminal calcium at the frog NMJ (44). Although the above observations suggest that the average level of calcium inside the terminal may not influence much synaptic vesicle retrieval, there is a possibility that when calcium enters and evokes exocytosis, it could activate the process of membrane internalization.

In the shibire fly, where endocytosis is arrested in a temperature-sensitive way, recovery of synaptic vesicles at permissive temperatures in retinal cells occurs by two pathways, one located in the retinal dense bodies and dependent on the presence of extracellular calcium, and the other that is independent of calcium and seems to be located at ectopic sites (57). A drastic calcium effect has been observed in goldfish bipolar cells, where high internal calcium concentration seemed to arrest endocytosis (45). However, care must be taken since it is possible that a decrease in the rate of membrane retrieval observed by membrane capacitance may also occur due to increasing rates of exocytosis (58). Thus, independent measurements of endocytosis may have to be performed in order to confirm the suggestion of inhibition of membrane retrieval by $\mathrm{Ca}^{2+}$ in goldfish bipolar cells. In addition, in chromaffin cells and other secretory cells that secrete granules, fast endocytosis requires $\mathrm{Ca}^{2+}$ (59). Interestingly, $\mathrm{Sr}^{2+}$ or $\mathrm{Ba}^{2+}$ was not able to replace $\mathrm{Ca}^{2+}$, suggesting a unique divalent cation requirement for the putative calcium sensor of secretory granules (59).

The above observations prompted us to examine the recycling of synaptic vesicles by FM1-43 imaging using confocal microscopy during substitution of $\mathrm{Sr}^{2+}$ by $\mathrm{Ca}^{2+}$ at the frog NMJ (32). In these experiments, internalization of FM1-43 after trains of nerve stimulation ( 2400 or 4800 pulses) was impaired in the presence of $\mathrm{Sr}^{2+}$ when compared to $\mathrm{Ca}^{2+}$-bathed muscles. This impairment could be reversed by increasing the number of pulses delivered to the axonal terminal (6000 action potentials) or by increasing the extracellular concentration of 
$\mathrm{Sr}^{2+}$ to $10 \mathrm{mM}$ (1.8 $\mathrm{mM}$ was normally used) during stimulation with 2400 action potentials. The exocytosis of vesicles was not altered by $\mathrm{Sr}^{2+}$ when compared to that seen in $\mathrm{Ca}^{2+}$ medium, suggesting that the inhibition of FM1-43 internalization by $\mathrm{Sr}^{2+}$ was not due to a decrease of vesicle fusion (32). Taken together, the results suggested that $\mathrm{Sr}^{2+}$ is much less effective than $\mathrm{Ca}^{2+}$ in supporting endocytosis, but upon reaching a certain threshold of intracellular concentration it triggers endocytosis.

If indeed $\mathrm{Ca}^{2+}$ is required to control the retrieval of synaptic vesicles, it becomes of interest to determine the identity of the putative calcium sensor for endocytosis similar to the postulated role of calmodulin in chromaffin granules (59). Synaptotagmin may be a candidate, in view of its ability to bind $\mathrm{Ca}^{2+}$ and to affect endocytosis. Dynamin also binds $\mathrm{Ca}^{2+}$ and its GTPase activity is controlled by this divalent ion (60). Moreover, activation of protein kinases or phosphatases may also be a target through which $\mathrm{Ca}^{2+}$ could influence the internalization of synaptic vesicles.

A number of important points therefore remain open, such as whether endocytosis presents distinct sensitivity to calcium compared to exocytosis, what is the identity of a putative calcium sensor for membrane internalization, which factors may control the rates of endocytosis, and finally whether other steps related to the recycling of vesicles are influenced by the intracellular concentration of calcium. Thus, in the near future, using the optical methods described herein, we can expect novel insights into the dynamics of membrane trafficking.

\section{References}

1. Reuser J E \& Reese TS (1973). Evidence for recycling of synaptic vesicle membrane during transmitter release at the frog neuromuscular junction. J ournal of Cell Biology, 57: 315-344.

2. Ceccarelli $B$, Hurbult WP \& Mauro A (1973). Turnover of transmitter and synaptic vesicles at the frog neuromuscular junction. J ournal of Cell Biology, 57: 499524.

3. Kelly RB (1993). Storage and release of neurotransmitters. Cell, 72 (Suppl): 43-53.

4. Betz WJ, Mao F \& Bewick GS (1992). Activity-dependent fluorescent staining and destaining of living vertebrate motor nerve terminals. J ournal of Neuroscience, 12: 363-375.

5. Betz WJ , Mao F \& Smith CB (1996). Imaging exocytosis and endocytosis. Current Opinion in Neurobiology, 6: 365-371.

6. Robitaille R, Adler EM \& Charlton MP (1990). Strategic location of calcium channels at transmitter release sites of frog neuromuscular junction. Neuron, 5: 773779.

7. Martin-Moutot N, Charvin N, Leveque $C$, Sato K, Nishiki T, Kosaki S, Takahashi M \& Seagar M (1996). Interaction of SNARE complexes with P/Q-type calcium channels in rat cerebellar synaptosomes. J ournal of Biological Chemistry, 271: 65676570.

8. Augustine GJ , Burns ME, De Bello WM, Pettit DL \& Schweizer FE (1996). Exocytosis: proteins and perturbations. Annual Review of Pharmacology and Toxicology, 36: 659-701.

9. Südhof TC (1995). The synaptic vesicle cycle: a cascade of protein-protein interactions. Nature, 375: 645-653.

10. Dodge J r FA \& Rahamimoff R (1967). Cooperative action of calcium ions in transmitter release at the neuromuscular junction. J ournal of Physiology, 193: 419-432.

11. Davletov BA \& Sudhof TC (1993). A single C2 domain from synaptotagmin I is sufficient for high affinity $\mathrm{Ca}^{2+} /$ phospholipid binding. J ournal of Biological Chemistry, 268: 26386-26390.

12. Chapman ER, An S, Edwardson JM \& J ahn R (1996). A novel function for the second C2 domain of synaptotagmin. $\mathrm{Ca}^{2+}$-triggered dimerization. J ournal of Biological Chemistry, 271: 5844-5849.

13. Geppert M, Goda Y, Hammer RE, Li C, Rosahl TW, Stevens CF \& Sudhof TC
(1994). Synaptotagmin I: a major $\mathrm{Ca}^{2+}$ sensor for transmitter release at a central synapse. Cell, 79: 717-727.

14. J orgensen EM, Hartwieg E, Schuske K, Nonet ML, J in Y \& Horvitz HR (1995). Defective recycling of synaptic vesicles in synaptotagmin mutants of Caenorhabditis elegans. Nature, 378: 196-199.

15. Fukuda $M$, Moreira JE, Lewis $F M$, Sugimori $M$, Niinobe $M$, Mikoshiba $K \&$ Llinas R (1995). Role of the C2B domain of synaptotagmin in vesicular release and recycling as determined by specific antibody injection into the squid giant synapse preterminal. Proceedings of the National Academy of Sciences, USA, 92: 10708-10712.

16. Sollner $T$, Whiteheart SW, Brunner $M$, Erdjument-Bromage $\mathrm{H}$, Geromanos $\mathrm{S}$, Tempst P \& Rothman JE (1993). SNAP receptors implicated in vesicle targeting and fusion. Nature, 362: 318-324.

17. Montecucco C \& Schiavo G (1993). Tetanus and botulinum neurotoxins: a new group of zinc proteases. Trends in Biochemical Sciences, 18: 324-327.

18. Ryan TA, Reuter $H$, Wendland $B$, Schweizer FE, Tsien RW \& Smith SJ 
(1993). The kinetics of synaptic vesicle recycling measured at single presynaptic boutons. Neuron, 11: 713-724.

19. Henkel AW, Lubke J \& Betz WJ (1996). FM 1-43 dye ultrastructural localization in and release from frog motor nerve terminals. Proceedings of the National Academy of Sciences, USA, 93: 1918-1923.

20. Angleson J K \& Betz WJ (1997). Monitoring secretion in real time: capacitance, amperometry and fluorescence compared. Trends in Neurosciences, 20: 281287.

21. Betz WJ \& Bewick GS (1992). Optical analysis of synaptic vesicle recycling at the frog neuromuscular junction. Science, 255: 200-203.

22. Betz WJ \& Bewick GS (1993). Optical monitoring of transmitter release and synaptic vesicle recycling at the frog neuromuscular junction. J ournal of Physiology, 460: 287-309.

23. Reuter H (1995). Measurements of exocytosis from single presynaptic nerve terminals reveal heterogeneous inhibition by $\mathrm{Ca}^{2+}$ channel blockers. Neuron, 14: 773779.

24. Meffert $M$, Premack BA \& Schulman $H$ (1994). Nitric oxide stimulates $\mathrm{Ca}^{2+}$-independent synaptic vesicle release. Neuron, 12: 1235-1244.

25. Smith CB \& Betz WJ (1996). Simultaneous independent measurement of endocytosis and exocytosis. Nature, 380: 531-534.

26. Pocock J M, Cousin MA, Parkin J \& Nicholls DG (1995). Glutamate exocytosis from cerebellar granule cells: the mechanism of a transition to an L-type $\mathrm{Ca}^{2+}$ channel coupling. Neuroscience, 67: 595607.

27. Guatimosim C, Romano-Silva MA, Cruz J S, Beirão PSL, Kalapothakis E, MoraesSantos T, Cordeiro MN, Diniz CR, Gomez MV \& Prado MAM (1997). A toxin from the spider Phoneutria nigriventer that blocks calcium channels coupled to exocytosis. British J ournal of Pharmacology, 122: 591-597.

28. Reuter H (1996). Diversity and function of presynaptic calcium channels in the brain. Current Opinion in Neurobiology, 6: 331337.

29. Cousin MA, Hurst H \& Nicholls DG (1997). Presynaptic calcium channels and fieldevoked transmitter exocytosis from cultured cerebellar granule cells. Neuroscience, 81: 151-161.

30. Mintz IM, Sabatini BL \& Regehr WG (1995). Calcium control of transmitter re- lease at a cerebellar synapse. Neuron, 15 : 675-688.

31. Ryan TA \& Smith SJ (1995). Vesicle pool mobilization during action potential firing at hippocampal synapses. Neuron, 14: 983-989.

32. Guatimosim C, Romano-Silva MA, Gomez MV \& Prado MAM (1998). Recycling of synaptic vesicles at the frog neuromuscular junction in the presence of strontium. J ournal of Neurochemistry, 70: 24772483.

33. Prado MAM, Romano-Silva MA, Beirão PSL, Collier B, Gomez MV \& Guatimosim C (1996). Calcium control of exocytosis measured by FM1-43 fluorescence in mammalian synaptosomes. Society for Neuroscience Abstracts, 22: 506.

34. Klingauf J , Kavalali E \& Tsien RW (1997). Evidence for fast endocytosis at single synapses of hippocampal neurons in culture. Annals of the International Conference " $L a$ transmission synaptique et sa modulation", 92 (Abstract).

35. Liu G \& Tsien RW (1995). Synaptic transmission at single visualized hippocampal boutons. Neuropharmacology, 34: 14071421.

36. Isaacson J S \& Hille B (1997). GABA (B)mediated presynaptic inhibition of excitatory transmission and synaptic vesicle dynamics in cultured hippocampal neurons. Neuron, 18: 143-152.

37. Ryan TA, Ziv NE \& Smith SJ (1996). Potentiation of evoked vesicle turnover at individually resolved synaptic boutons. Neuron, 17: 125-134.

38. Ryan TA, Reuter H \& Smith SJ (1997). Optical detection of a quantal presynaptic membrane turnover. Nature, 388: 478482.

39. Kraszewski $K$, Mundigl $O$, Daniell $L$, Verderio C, Matteoli $M$ \& De Camilli $P$ (1995). Synaptic vesicle dynamics in living cultured hippocampal neurons visualized with CY3-conjugated antibodies directed against the lumenal domain of synaptotagmin. J ournal of Neuroscience, 15: 4328-4342.

40. Lang T, Wacker I, Steyer J, Kaether C, Wunderlich I, Soldati T, Gerdes HH \& Almers W (1997). Ca ${ }^{2+}$-triggered peptide secretion in single cells imaged with green fluorescent protein and evanescent-wave microscopy. Neuron, 18: 857863.

41. Steyer JA, Horstmann $H \&$ A Almers $W$ (1997). Transport, docking and exocytosis of single secretory granules in live chromaffin cells. Nature, 388: 474-478.
42. Henkel AW, Simpson LL, Ridge RM \& Betz WJ (1996). Synaptic vesicle movements monitored by fluorescence recovery after photobleaching in nerve terminals stained with FM 1-43. J oumal of Neuroscience, 16: 3960-3967.

43. Betz WJ \& Henkel AW (1994). Okadaic acid disrupts clusters of synaptic vesicles in frog motor nerve terminals. J ournal of Cell Biology, 124: 843-854

44. Wu LG \& Betz WJ (1996). Nerve activity but not intracellular calcium determines the time course of endocytosis at the frog neuromuscular junction. Neuron, 17: 769779 .

45. Von Gersdorff H \& Matthews G (1994). Inhibition of endocytosis by elevated calcium in a synaptic terminal. Nature, 370: 652-655.

46. Maycox PR, Link E, Reetz A, Morris SA \& $J$ ahn R (1992). Clathrin-coated vesicles in nervous tissue are involved primarily in synaptic vesicle recycling. J ournal of Cell Biology, 118: 1379-1388.

47. Gonzalez-Gaitan M \& J ackle H (1997). Role of Drosophila alpha-adaptin in presynaptic vesicle recycling. Cell, 88: 767776.

48. Zhang JZ, Davletov BA, Sudhof TC \& Anderson RG (1994). Synaptotagmin I is a high affinity receptor for clathrin AP-2: implication for membrane recycling. Cell, 78: 751-760.

49. Powell KA \& Robinson PJ (1995). Dephosphin/dynamin is a neuronal phosphoprotein concentrated in nerve terminals: evidence from rat cerebellum. Neuroscience, 64: 821-833.

50. Koenig J H, Saito K \& Ikeda K (1983). Reversible control of synaptic transmission in a single gene mutant of Drosophila melanogaster. J ournal of Cell Biology, 96: 1517-1522.

51. Takei K, McPherson PS, Schmid SL \& De Camilli $P$ (1995). Tubular membrane invaginations coated by dynamin rings are induced by GTP- $\gamma S$ in nerve terminals. $\mathrm{Na}$ ture, 374: 186-190.

52. Shupliakov O, Low P, Grabs D, Gad H, Chen H, David C, Takei K, De Camilli P \& Brodin L (1997). Synaptic vesicle endocytosis impaired by disruption of dynaminSH3 domain interactions. Science, 276: 259-263.

53. Meldolesi J \& Ceccarelli B (1981). Exocytosis and membrane cycling. Philosophical Transactions of the Royal Society of London, B296: 55-65.

54. Ryan TA, Smith SJ \& Reuter H (1996). The timing of synaptic vesicle endocyto- 
sis. Proceedings of the National Academy of Sciences, USA, 93: 5567-5571.

55. Henkel AW \& Betz WJ (1995). Staurosporine blocks evoked release of FM 1-43 but not acetylcholine from frog motor nerve terminals. J ournal of Neuroscience, 15: 8246-8258.

56. Ceccarelli B \& Hurlbut W (1980). $\mathrm{Ca}^{2+}$ dependent recycling of synaptic vesicles at the frog neuromuscular junction. J our- nal of Cell Biology, 87: 297-303.

57. Koenig JH \& Ikeda K (1996). Synaptic vesicles have two distinct recycling pathways. J ournal of Cell Biology, 135: 767808.

58. Lagnado L, Gomis A \& J ob C (1996). Continuous vesicle cycling in the synaptic terminal of retinal bipolar cells. Neuron, 17: 957-967.

59. Artalejo CR, Elhamdani $A \&$ Palfrey HC
(1996). Calmodulin is the divalent cation receptor for rapid endocytosis, but not exocytosis, in adrenal chromaffin cells. Neuron, 16: 195-205.

60. Liu J P, Zhang QX, Baldwin G \& Robinson PJ (1996). Calcium binds dynamin and inhibits its GTPase activity. J ournal of Neurochemistry, 66: 2074-2081. 